\title{
La potencia como medio de diferenciación en la inmanencia. Deleuze, lector de Schelling, lectores de Spinoza.
}

\author{
Gonzalo Santaya \\ Consejo Nacional de Investigaciones Científicas y Técnicas (CONICET)/ \\ Universidad de Buenos Aires \\ gonsantaya@gmail.com \\ https://orcid.org/0000-0002-1998-6215
}

Resumen: Este artículo busca analizar el concepto deleuziano de potencia, trazando una genealogía que lo asocia con la filosofia de Schelling -inspirado, a su vez, en Spinoza-, con la finalidad de mostrar el modo en que dicho concepto puede funcionar como el medio para pensar la multiplicidad de diferenciaciones e individuaciones del Ser en el contexto de la filosofia de la inmanencia. Para ello, reconstruiremos la presencia de Schelling en el concepto de potencia tal como Deleuze lo desarrolla en sus obras de 1968: Diferencia y repetición y Spinoza y el problema de la expresión. A continuación, exponemos las notas principales de ese concepto tal como Schelling lo presenta en las obras mencionadas por Deleuze (particularmente, Lecciones privadas de Stuttgart, de 1810, y Las edades del mundo, de 1815). Finalmente, desarrollamos comparativamente la especificidad de la potencia deleuziana en su doble aspecto: como potencia ideal e intensiva, para mostrar el modo en el cual ella articula el proceso de individuación en la inmanencia.

Palabras clave: Deleuze; Schelling; potencia; inmanencia; Spinoza

\begin{abstract}
Power as a Means of Differentiation in Immanence. Deleuze, Reader of Schelling, Readers of Spinoza". This paper seeks to analyze the Deleuzian concept of potency, by drawing a genealogy that traces it back to Schelling's philosophy -who is, in turn, inspired by Spinoza-, with the aim of showing how that concept can help us to think the way in which Being is differentiated and individuated within the philosophy of immanence. In order to do this, we will summarize Schelling's presence in Deleuze's concept of potency, as he develops it in his two books from 1968: Difference and Repetition and Expressionism in Philosophy. We will then expose the main features of that concept following the works of Schelling mentioned by Deleuze (particularly, the Stuttgart Private Lessons, from 1810, and The Ages of the World, from 1815). Finally, we will develop the specificity of the Deleuzian concept of potency in its double aspect: as ideal potency and as intensive potency, to show the way in which it articulates an immanent individuation process.
\end{abstract}

Keywords: Deleuze; Schelling; potency; immanence; Spinoza 


\section{Introducción}

Retomemos dos acusaciones célebres contra dos de los principales exponentes de la filosofia de la inmanencia: contra Schelling por su "indiferencia" (en la velada crítica hegeliana a su ontologia, que evoca la noche de las vacas negras) ${ }^{1}$; y contra Deleuze por "ideólogo del capitalismo tardío" 2 . Si bien estas criticas parten de posturas diversas y sus motivaciones no necesariamente provienen de una reacción contra la inmanencia en tanto tal, tienen en común el denostar estos planteos inmanentistas sobre la base de sus supuestas consecuencias nocivas (sean estas de orden religioso, moral, epistémico o político). Las doctrinas de estos autores conducirian, en el mejor de los casos, a un abierto rechazo de todo orden moral del mundo y, consecuentemente, a un llamado al quietismo hedonista o incluso a convalidar la miseria y la opresión.

En este trabajo nos dedicaremos a revisar la noción de potencia, bajo la hipótesis de que ella reaparece en estas filosofias a través de un cierto uso común, que las provee de un criterio positivo de diferenciación simultáneamente ontológico, gnoseológico y ético, el cual las aleja de toda forma de indiferencia. Nos centraremos para este análisis en la presencia de Friedrich Schelling en Gilles Deleuze: concretamente, en la obra ontológica capital de este último, Diferencia y repetición, donde se elabora una noción de potencia para una filosofia inmanentista contemporánea, en el espíritu de un spinozismo que atraviesa las épocas, los problemas y los conceptos de esos dos filósofos. Pretendemos mostrar que, rescatando el tratamiento schellingiano de la potencia, Deleuze traza un movimiento filosófico que entreteje la dimensión "ideal" o trascendental

1 Cf. Hegel, G.W.F., Fenomenología del Espiritu, Buenos Aires: Fondo de Cultura Económica, 2009, p. 15.

2 Zizek, S., Órganos sin cuerpo. Sobre Deleuze y sus consecuencias, Valencia: Pre-textos, 2015, p. 209. Sería interesante rastrear el vínculo entre estas críticas a Schelling y a Deleuze con aquellas que suscitó Spinoza en la historia de la filosofia de la inmanencia, por dogmático, fatalista, ateo y nihilista. Ellas protagonizan la polémica del spinozismo, llevada a su auge por Jacobi en el contexto del naciente Idealismo Alemán ( $c f$. Jacobi, F.H., "Cartas sobre la doctrina de Spinoza al señor Moses Mendelssohn”, en: El ocaso de la ilustración. La polémica del spinozismo, Solé, M.J. (trad.), Bernal: Universidad Nacional de Quilmes, 2013, en especial p. 137 y ss.). La acusación a Spinoza de "dogmático", enfatizada por Fichte ( $c f$. Fichte, J.G., Fundamento de toda la Doctrina de la ciencia, en: Doctrina de la ciencia, Buenos Aires: Aguilar, 1975, p. 32 y 57), es -como veremos aquí- mantenida por Schelling, quien no por eso deja de reconocerse spinozista. El análisis de estas críticas, sin embargo, excede largamente el objetivo de este trabajo. 
y la "real" o empírica, de manera que articula un campo trascendental definido por la distribución de puras singularidades con el plano empírico de su actualización, poblado de diversos individuos cualificados y extensos en interacción reciproca. En ese contexto, la caracterización de la inmanencia como indiferencia ontológica, epistémica o práctica, o como llamado a un quietismo cínico o hedonista en el seno de la actual sociedad de consumo, será puesta en entredicho.

\section{El problema de la potencia en Deleuze}

\subsection{La potencia como nudo entre la repetición y la diferencia}

La noción de potencia aparece en numerosas oportunidades en Diferencia y repetición con una fuerte impronta ontológica, aunque no siempre parece-al menos en principio- significar lo mismo. A grandes rasgos, podemos distinguir dos campos temáticos en los que Deleuze recurre a esa noción: la esencia de la repetición como potencia de una singularidad pre-individual y la potencia como capacidad de actuar de un individuo. Estos temas se vinculan con el propósito que Deleuze se plantea al inicio de esa obra, a saber: elaborar conceptos positivos de la diferencia $y$ de la repetición, superando la negatividad a la que se las somete desde la lógica que las subordina a la identidad del concepto representativo. Los conceptos "de una diferencia pura y de una repetición compleja" se reúnen y confunden a lo largo de la investigación deleuziana, y la potencia es en ella un punto clave que está presente en ambos conceptos.

Desde las primeras páginas de la Introducción a Diferencia y repetición, encontramos la definición de la repetición como "enésima potencia" de una singularidad. La singularidad como categoría propiamente ontológica se distingue del ámbito de la generalidad y de la particularidad asociadas a la lógica representativa. Pensada desde esta lógica, la repetición se manifiesta en una serie de objetos conceptualmente idénticos y sensiblemente semejantes, mutuamente exteriores y sucesivos, en el espacio y/o en el tiempo. Esto reduce a la repetición a una mera negación extra-conceptual (para una serie de repeticiones de algo que cae bajo el mismo concepto: el segundo es el que no es el primero; el tercero, el que no es el segundo ni el primero; etcétera). Pero esa negación sugiere (sin decir cómo ni por qué) que lo que se repite no puede ser algo estrictamente idéntico a sí mismo; si lo fuera, no sería propiamente una repetición, sino una permanencia. La repetición no se explica desde un orden

3 Deleuze, G., Différence et répétition, París: PUF, 1968, p. 2; en todos los casos la referencia a la obra de Deleuze refiere a la paginación de la primera edición francesa y la traducción es nuestra. 
de regularidad legaliforme, porque los términos de la serie de repeticiones no encajan completamente bajo una misma representación idéntica (si se repite, no es la misma cosa). Podemos, como Kant, afirmar el ámbito de la intuición como un ámbito completamente ajeno a lo conceptual, el cual provee un criterio de diferenciación a lo repetido; con esto, sin embargo, eludimos la creación de un concepto positivo de la repetición, que Deleuze buscaba-además de caer en el problema de la separación entre intuición y concepto.

Sin embargo, parece que un auténtico concepto de la repetición debe aprehenderla -paradójicamente- como algo ajeno a lo conceptual, o bien al orden representativo que el concepto instaura. Lo repetido debe ser entonces cada vez algo único o singular y la repetición debe expresar una potencia de esa singularidad: no la manifestación de un múltiple pasible de ser unificado en un concepto, sino la capacidad de ponerse de una vez como multiplicidad. "No se trata de agregar una segunda y una tercera vez a la primera, sino de llevar la primera vez a la enésima potencia. Bajo esta relación de potencia, la repetición se invierte, interiorizándose... [La repetición] expresa una singularidad contra la generalidad, una universalidad contra la particularidad"4. Singularidad y universalidad interiorizan la repetición, contra la generalidad conceptual y la particularidad sensible que la conciben como negación extrínseca. La singularidad difiere entonces del orden de la representación conceptual. Si la repetición interioriza la diferencia que la hace posible, la singularidad que se pone $n$ veces es una potencia de diferenciación. Esto nos lleva al siguiente punto.

El segundo uso deleuziano de la potencia refiere a la capacidad de una cosa de "ir hasta el final de lo que puede". Esto se da en la caracterización del ser como unívoco, en el marco del primer capítulo de Diferencia y repetición ("La diferencia en sí misma”). Allí Deleuze rechaza los planteos que establecen una distinción categorial de los entes en el ser según una distribución basada en limites fijos que los definen y organizan en una escala jerárquica, de acuerdo a su cercanía o distancia respecto a un principio. La apuesta deleuziana es la de una ontología univocista en la que el ser se diga en un único y mismo sentido para todos los entes o diferencias individuales. Esto implica otro tipo de jerarquía, una "que considere a las cosas y a los seres desde el punto de vista de la potencia: no se trata de grados de potencia considerados absolutamente, sino de saber si un ser 'salta' eventualmente, es decir, si sobrepasa sus limites, yendo hasta el final de lo que puede"5. El límite no designa aquí las

\footnotetext{
Ibid., pp. 8-9.

Ibid., p. 55.
} 
"parcelas" fijas de una distribución sedentaria -como la tabla de las especies de Linneo-, ni grados determinados de una única esencia, sino la condición de cierta actividad transformadora: "aquello a partir de lo cual la cosa se despliega, y despliega toda su potencia"6. La potencia determina entonces la capacidad de actuar de una cosa, en la medida en que esa capacidad implica sobrepasar sus limites constitutivos, superando lo que la define y, por lo tanto, difiriendo de sí misma. Aquí, potencia y límite se presuponen mutuamente. Si la potencia implica ir hasta el final de lo que se puede, y "saltar" -devenir otro, desplazar o reconfigurar los limites-, ella expresa una fuerza de la diferencia que, nuevamente, no encaja en el orden de la identidad conceptual sino en la medida en que lo transgrede (el límite solo sería insuperable en el marco del concepto representativo, que define a las cosas por lo que son, sin entender por ello lo que pueden ser, su poder de devenir).

La esencia de la repetición conduce del orden de las cosas que se repiten al orden de la potencia de una singularidad; la jerarquización de los entes en el ser conduce de la univocidad del mismo a la capacidad de actuar específicamente individual de cada ente, en tanto "modo" del ser. Si consideramos el hecho de que, en la obra deleuziana, el concepto de "singularidad" se vincula a lo pre-individual (o al campo trascendental que es condición genética de la experiencia real de los seres individuados), y que la capacidad de actuar es, en cada caso, la propia de un individuo concreto, entonces la noción de potencia -en su doble acepción, como capacidad de la singularidad de ponerse $n$ veces y capacidad de un individuo de sobrepasar sus límites- aparece, así, como una posible clave para pensar el problema de la relación entre lo ideal y lo efectivo, entre lo pre-individual y el individuo. La pregunta, entonces, que dejamos planteada para lo que sigue es la siguiente: ¿cómo se vinculan esos dos usos de "potencia"?

\subsection{Las potencias de Schelling en Deleuze}

A la luz de esta pregunta, las citas y referencias a Schelling que encontramos en la obra deleuziana se vuelven muy significativas, a pesar de ser escasas. Si bien "potencia" guarda -para Deleuze y sus lecturas- fuertes resonancias nietzscheanas, spinozistas, e incluso matemáticas, Schelling es, al respecto, una figura ineludible: en las dos grandes obras que Deleuze presenta en 1968 (Spinoza y el problema de la expresión y Diferencia y repetición), el

$6 \quad$ Ibid., p. 55. 
idealista alemán aparece mencionado, a raíz de su teoría de las potencias, en dos contextos que comparten un problema común: precisamente, el del cruce entre lo ideal y lo efectivamente existente, o entre lo virtual y lo actual. Más de 20 años después del '68, lejos del contexto de producción de estas obras, encontramos en ¿Qué es la filosofía? -escrito en 1991 junto a Félix Guattari- la siguiente reflexión: "los conceptos son y permanecen firmados: sustancia de Aristóteles, cogito de Descartes, mónada de Leibniz, condición de Kant, potencia de Schelling, duración de Bergson..."7. Deleuze caracteriza a Schelling como el filósofo de la potencia, aquel que dejó su firma en ese concepto para la posteridad.

En Spinoza y el problema de la expresión, al analizar la célebre proposición 7 del libro II de la Ética -según la cual "El orden y conexión de las ideas son los mismos que el orden y conexión de las cosas"8-, Deleuze se refiere a las Lecciones privadas de Stuttgart de Schelling para explicar el paralelismo spinozista como fundado en dos potencias infinitas de Dios. Deleuze escribe: "Las dos potencias no tienen pues nada de relativo: son las mitades del absoluto, las dimensiones del absoluto, las potencias del absoluto. Schelling es spinozista cuando desarrolla una teoría del absoluto representando a Dios por el simbolo $A^{3}$, que comprende lo real y lo ideal como sus potencias".

De acuerdo con la lectura deleuziana, el Dios de Spinoza-unidad en tanto sustancia, multiplicidad en tanto esta se diversifica en atributos y modos-, posee dos potencias: potencia infinita de existir y actuar (la realidad formal de Dios, cuya esencia son sus infinitos atributos, constituye la primera potencia), y potencia infinita de pensar (la realidad objetiva de Dios, o auto-comprensión de su esencia, en la que una idea corresponde a cada atributo y una a cada modo, constituye la segunda potencia). La primera potencia concierne a los atributos divinos (equivalentes entre sí en relación a esta potencia) y a sus modificaciones; la segunda potencia, en cambio, posee una relación especial con el atributo pensamiento, sin identificarse con él. Si bien no todos los modos de la sustancia

7 Deleuze, G. y F. Guattari, Qu'est-ce que la philosophie?, París: Les éditions de minuit, 1991, p. 13 (traducción y cursivas nuestras).

$124 \quad$ Spinoza, B., Ética demostrada según el orden geométrico, Ciudad de México: Porrúa, 1997, p. 38.

9 Deleuze, G., Spinoza et le problème de l'expression, París: Les éditions de minuit, 1968, p. 104 (traducción y cursivas nuestras). La breve reconstrucción que sigue a continuación se basa en las páginas subsiguientes de esa obra deleuziana (hasta p. 113). También en ¿Qué es la filosofia?, Deleuze y Guattari retoman esta dualidad de potencias como el momento fundamental de la inmanencia spinozista, luego del conocido pasaje en el que condecoran a Spinoza con el título de "príncipe de los filósofos": "[El plano de inmanencia] nos tiende sus dos caras, la extensión y el pensamiento, o más exactamente sus dos potencias, potencia de ser y potencia de pensar" (Deleuze, G. y F. Guattari, Qu'est-ce que la philosophie?, p. 52). 
son pensantes, sí son pensados en virtud de esa segunda potencia divina, pues les corresponde una idea en el atributo pensamiento: "todo aquello que participa de la potencia de existir y de actuar, bajo tal o cual atributo, participa también de la potencia de pensar, pero en el mismo atributo pensamiento"10. Esto vale incluso para los propios modos del atributo pensamiento (ideas), por lo que la segunda potencia introduce en la esencia divina una capacidad de reflexionarse al infinito (idea de la idea...). Ambas potencias, en tanto "mitades" del absoluto, constituyen una unidad a causa de la unidad de la sustancia infinita (que Schelling llamará $\mathrm{A}^{3}$, como veremos), y en virtud de esa unidad, cada modo es uno con la idea que le corresponde, conformando un individuo ${ }^{11}$.

El proceso de constitución de un individuo en términos de potencias es retomado durante la exposición de la propia ontología deleuziana, en Diferencia y repetición (concretamente en el Capitulo IV, "Síntesis ideal de la diferencia"). Allí, Deleuze echa mano a la noción schellingiana de potencia al abordar el problema de la relación entre lo virtual (o ideal) y lo actual (el orden de lo particular concreto, la existencia cualitativa espacio-temporal). Ya mencionamos que la noción de singularidad se vincula en Deleuze con una dimensión extra-representativa y pre-individual. Agregamos ahora que esta dimensión está definida por el concepto deleuziano de Idea -que Deleuze desarrolla en el mencionado Capítulo IV-, como un complejo diferencial virtual que se encarna en la existencia actual. La actualización de la Idea implica una "condensación de singularidades". Describiendo ese proceso trascendental que hace "estallar la Idea en lo actual"12, Deleuze escribe: "Lo más importante en la filosofía de Schelling es la consideración de las potencias. Y qué injusta es la crítica de Hegel a este respecto, sobre las vacas negras. De los dos filósofos, es Schelling quien sabe hacer salir la diferencia de la noche de lo idéntico con relámpagos más finos, más variados, más terroríficos también que los de la contradicción: con progresividad. La cólera y el amor son las potencias de la Idea que se desarrollan a partir de un $\mu$ j̀ óv, es decir, no un negativo o un no-ser (oúk óv), sino de un ser problemático o de un no-existente, ser implícito de las existencias más allá del fundamento. El Dios del amor y el Dios de la cólera no están de más para tener una idea. $\mathrm{A}, \mathrm{A}^{2}, \mathrm{~A}^{3}$ forman el juego de la despotencialización y

\footnotetext{
10 Deleuze, G., Spinoza et le problème de l'expression, p. 109.

11 Ibid., p. 112: "Un modo en tal atributo forma con la idea que lo representa un "individuo" irreductible; y también una idea, en el atributo pensamiento, con el objeto que ella representa... Así, la misma modificación no existe solamente en una infinidad de modos, sino en una infinidad de individuos, cada uno constituido por un modo y por la idea de ese modo".

12 Deleuze, G., Différence et répétition, p. 246.
} 
la potencialidad pura, testimoniando en la filosofia de Schelling la presencia de un cálculo diferencial adecuado a la dialéctica"13.

La referencia aquí es, además de a las ya mencionadas Lecciones privadas de Stuttgart a Las edades del mundo (ambas obras en su edición en lengua francesa a cargo de Aubier, traducidas por Vladimir Jankélévitch). Un análisis exhaustivo de los conceptos deleuzianos envueltos en esta cita excedería los limites del presente trabajo; nos limitaremos a señalar cómo el tema de las potencias schellingianas se presenta aquí en el contexto del problema filosófico de la construcción de una ontología de la Idea que se expresa en una existencia individual ${ }^{14}$.

En efecto, la obra de Schelling se elabora y reelabora en torno al proyecto de construir un sistema que dé cuenta de la relación entre la dimensión natural-real-necesaria de la existencia y de la dimensión espiritual-ideal-libre de la Idea. Spinoza y Fichte se encuentran y entrelazan en ese pensamiento conflictivo que intenta conjugar sus perspectivas ontológicas en una filosofia del Absoluto, en su doble manifestación: naturaleza y espíritu. La filosofia de las potencias de Schelling se aboca de lleno a ese problema, para lo cual despliega -entre muchos otros- los tópicos que Deleuze retoma en el fragmento citado: las fuerzas contrapuestas del amor y la cólera, la progresividad, la contraposición con la dialéctica hegeliana, el no-ser por encima del mero no-existente, la pura potencialidad, etcétera. El recorrido por esas obras de Schelling está cargado de resonancias deleuzianas. Nos interesa, pues, abordarlas en torno a la cuestión de las dos acepciones de la potencia deleuziana previamente expuestas. Dedicamos la sección siguiente a reconstruir esos tópicos en el propio contexto de la obra schellingiana, para luego volver a Deleuze y sus potencias.

\section{La Potenzenlehre schellingiana}

\subsection{Las Investigaciones de 1809, germen de la Potenzenlehre}

En la vasta obra de Schelling, la doctrina de las potencias se reduce a un período de su pensamiento particularmente oscuro que se inicia con su célebre

126 texto de 1809: Investigaciones filosóficas sobre la esencia de la libertad humana

\footnotetext{
13 Ibid., p. 246. Cursivas nuestras.

${ }^{14}$ Este es un tema de relativa actualidad en los estudios deleuzianos, que, sin embargo, no ha sido considerado - hasta donde alcanza nuestro conocimiento- bajo la luz de la figura de Schelling (cf. Clisby, D., “¿El dualismo secreto de Deleuze?”, en: Ideas, Revista de filosofia moderna y contemporánea, 4 (2016), pp. 120-148; y también el número 2 del volumen XI (2017) de Deleuze $\&$ Guattari Studies, integramente dedicado a las relaciones entre lo virtual y lo actual).
} 
y los objetos con ella relacionados ${ }^{15}$. Esta publicación marca un quiebre respecto a su trabajo de juventud, que desde 1795 lo colocaba en el centro de la escena intelectual en la que surgía como el discípulo más destacado de Fichte al desarrollar un idealismo "subjetivo" donde el Yo es principio y la intuición intelectual es método, para pasar luego por una etapa "objetiva" donde desarrollaba su filosofía de la naturaleza -que deduce el ser de la materia y sus leyes a partir de procesos dinámicos, combinando el idealismo con la fisica y química de su tiempo-, y, consiguientemente, para formular su filosofia de la identidad, que integraba las etapas anteriores como momentos contrapuestos y necesarios del desarrollo de lo Absoluto ${ }^{16}$. Luego de publicar las Investigaciones en 1809, Schelling se vuelca a una época "silenciosa", consumida en la producción del ambicioso proyecto, interrumpido, recomenzado y nunca concluido, de Las edades del mundo, el cual desarrollaremos en la siguiente sección.

El problema fundamental de las Investigaciones es el de la efectividad del mal y la alternativa de la inmanencia frente al mismo: o bien el mal carece de efectividad real, o bien tiene realidad, y, en consecuencia, forma parte del ser perfecto. La respuesta de Schelling, sin dejar de ser una defensa del spinozismo, implica una ruptura y una distancia crítica con este. Su compleja postura pretende incluir la dualidad bien-mal al interior del despliegue, simultáneamente libre y necesario, del Absoluto. De hecho, las Investigaciones se proponen conciliar el sistema de la inmanencia con el concepto de libertad (o, en sus términos, el panteísmo con el idealismo), lo cual obliga a señalar las deficiencias del idealismo precedente -esto es, Fichte-. Ese idealismo no ha dado sino un concepto "general y formal" de la libertad y carece de un concepto "real y vivo de la misma"17. Esta crítica se solapa con la dirigida al spinozismo,

15 De aquí en adelante nos referiremos a él como Investigaciones.

16 Sobre esta evolución y el contexto de producción de las Investigaciones, remitimos a Leyte, A. y V. Rühle, "Estudio introductorio", en: Schelling, F.W.J., Investigaciones filosóficas sobre la esencia de la libertad humana y los objetos con ella relacionados, Cortés, H. y A. Leyte (trads.), Barcelona: Anthropos, 1989, pp. 6ss. Como indican los autores (cf. ibid., p. 19), la aproximación por etapas a la obra de Schelling no debe perder de vista que ella constituye un devenir cuyos momentos no están en relaciones de mutua ruptura, sino que engloban una constelación de problemas explorados desde distintas aproximaciones, interrelacionados en el proyecto de una filosofia del Absoluto. No hay que confundir este proyecto con el que Hegel inicia implacablemente pocos años más tarde. Schelling presenta una suerte de "culminación del idealismo" por medios bien distintos a los de Hegel, iniciando para la filosofia vias novedosas que serán más tarde exploradas por Schopenhauer, Kierkegaard e incluso Nietzsche y Heidegger.

17 Sobre esta dicotomía, y sobre el dilema del panteísmo respecto al problema del mal, cf. Schelling, F.W.J., SW VII, 351-2, pp. 147-151. En todas las referencias a Schelling seguiremos la paginación de sus obras completas en: Sämmlitche Werke, editadas por K.F.A. Schelling, Stuttgart y Augsburgo: Cotta, 1856-1861, según el siguiente formato: SW n. ${ }^{\circ}$ de tomo, $\mathrm{n}^{\circ}$ de página; en el 
por su carácter "cosista". Dice Schelling: "El fallo de su sistema [el de Spinoza] no reside en modo alguno en que sitúe las cosas en Dios, sino en que sean cosas: reside en el concepto abstracto de los seres del mundo, esto es, en el de la propia sustancia infinita, que para él es también a su vez una cosa"18. El spinozismo se vuelve por esto "un sistema realista y unilateral" 19 . Se trata de generar un concepto "real y vivo" de la libertad, a la vez que un panteísmo no cosificante que incluya la dimensión ideal y la articule con la real. Schelling quiere permanecer, sin embargo, en el espíritu del spinozismo: su apuesta es redefinir a Dios como causa inmanente del mundo, de manera que se responda a las acusaciones entonces comunes al panteísmo mediante la elevación de la libertad de Dios a la categoría superior y la caracterización de un ámbito específico para la libertad propiamente humana.

Si el rasgo distintivo de la filosofia hegeliana es pretender alcanzar la cima del sistema completo de la razón auto-cognoscente, el punto cúlmine del concepto devenido Idea absoluta, donde "el todo, su génesis y desarrollo" quedan finalmente subsumidos, la filosofia de Schelling -especialmente a partir de 1809- manifiesta una crisis de la razón ${ }^{20}$, una incapacidad constante de cerrarse sobre sí misma y la necesidad de una contracara irracional que ella debe suponer para poder ponerse y pensarse en la existencia. Desde las Investigaciones en adelante, el proyecto de Schelling busca dar cuenta de una historia de Dios, en la que el punto de vista divino no es jamás una apacible y transparente auto-contemplación del Absoluto en la totalidad armónica de sus figuras, sino un devenir viviente, y como tal, no exento de sufrimientos y oscuridades. En palabras de Arturo Leyte, durante las Investigaciones "se recrea la absoluta tensión permanente y dramática entre la unidad y la diferencia, y se hace nada menos que inscribiendo esa tensión en el ser mismo de Dios, a la vez que comprendiendo al hombre como órgano vinculante de ese drama" ${ }^{21}$.

La originalidad de este planteamiento pasa por distinguir entre la existencia de Dios y el fundamento de esa existencia. Esa distinción inscribe en Dios mismo un drama del que el hombre será actor. Dios es a la vez necesidad

caso de las Investigaciones, seguimos la traducción de Cortés y Leyte en Investigaciones filosóficas sobre la esencia de la libertad humana y los objetos con ella relacionados, indicando su paginación entre corchetes a continuación de la referencia a las SW.

${ }^{18} \mathrm{SW} \mathrm{I} / 7,349$ [141].

${ }^{19} \mathrm{SW} \mathrm{I} / 7,350$ [143].

${ }^{20}$ La caracterización de esta crisis y su relación con la filosofia de las potencias ha sido desarrollada por Laffoucrière, O., "Schelling et les puissances", en: Les études philosophiques, 2 (abriljunio de 1974), pp. 178ss.

${ }^{21}$ Leyte, A., Las épocas de Schelling, Madrid: Akal, 1998, p. 31. Las cursivas son nuestras. 
y libertad, naturaleza y espíritu. Necesidad o naturaleza constituyen el fundamento de su existencia, mientras que libertad o espíritu constituyen la esencia de Dios, la cual se realiza en la existencia erigiéndose sobre ese fundamento. Este último es ese núcleo oscuro irracional que se cierra sobre la luz de la razón, pero que, a la vez, le permite a esta volverse concreta, reflejarse sobre algo que no es ella misma y, de ese modo, conocerse y desplegarse. En este esquema, el hombre no se vuelve pecador porque tiene un cuerpo o inclinaciones sensibles naturalmente inmorales, sino porque en él reside este mismo conflicto de principios opuestos coexistentes en el ser primigenio.

El drama de Dios, drama de la existencia toda, es el de un devenir desde la oscuridad hacia la luz, de la naturaleza hacia la libertad, o de lo irracional a la razón. Este drama supone una construcción interna ${ }^{22}$, un despliegue gradual23, o una escisión progresiva ${ }^{24}$ de las fuerzas en conflicto que determinan un proceso de creaciones sucesivas cuyo punto más elevado es el hombre. En él, el drama de las fuerzas se traduce en la libertad especificamente humana, caracterizada como una capacidad para el bien o para el mal. Si el hombre se vuelca hacia lo que en él es el principio luminoso, reflejando el orden total de la creación, mediante el sentimiento de la religiosidad, actúa de acuerdo al bien. En cambio, el hombre deviene pecador si se vuelve hacia el principio oscuro, como aquello que lo encierra en su individualidad y lo afirma en su propia voluntad particular, con lo cual genera una desarmonía en sus fuerzas constituyentes. Dios es el ser supremo porque en él la libertad es la efectiva puesta acto-sin constricción- de una necesaria sumisión del principio oscuro -el fundamento de la existencia, o aquello que, en Dios, no es Dios-, posibilitando y dirigiendo el despliegue progresivo del universo. La existencia concreta -de Dios y de su creación- tiene su fundamento en esta naturaleza oscura, en la medida en que ella prepara el suelo para la libertad. En efecto, la auténtica filosofia de la naturaleza supone el concepto superior de la libertad, en el que "reside el último acto potenciador gracias al cual toda la naturaleza se transfigura en sensación, en inteligencia, y finalmente, en voluntad"25. En qué medida estamos o no aquí todavía en el esquema fichteano (del conflicto entre Yo y no-Yo) es una discusión en la que no podemos entrar en este artículo. En cualquier caso, la noción de potencia como mecanismo articulador de este despliegue aparece como una originalidad propiamente schellingiana que ya se preanuncia en las Investigaciones.

\footnotetext{
22 Cf. SW I/7, $362[171]$.

${ }^{23}$ Cf. SW I/7, 362 [173].

${ }^{24}$ Cf. SW I/7, 363 [175].

25 SW I/7, 350 [145]. Las cursivas son nuestras.
} 
Esta vía teleológica que va de la naturaleza a la voluntad consciente como despliegue de potencias será retomada y profundizada en la obra inmediatamente posterior de Schelling, junto con varios tópicos de las Investigaciones. En primer lugar, la identidad entre lo real y lo ideal, que Schelling ya había afirmado en etapas anteriores de su pensamiento ${ }^{26}$, deviene ahora un conflicto, una unidad viva de fuerzas en tensión. En segundo lugar, la subordinación de lo real a lo ideal (o del mal al bien, o de lo oscuro a la luz) es condición necesaria de la existencia efectiva y de la (auto)revelación de Dios. En tercer lugar, se destaca el carácter constructivo, dinámico y gradual de esa revelación. Por último, aparece en las Investigaciones la noción en la que se basa esa identidad ideal-real previa a la subordinación: el in-fundamento (Ungrund), profundidad sin fondo, anterior a todo fundamento y a toda dualidad, coexistencia de los principios por encima de la oposición. El in-fundamento designa una indeterminación primigenia más allá del bien y del mal, más allá de la existencia y su fundamento, y en la cual el conflicto eterno tiene su sede ${ }^{27}$. Esto es lo que habilita la progresiva (auto)revelación de Dios, su camino hacia el volverse uno. Este camino está impulsado por el amor que expresa el principio superior en Dios, al cual Schelling concede una consistencia ontológica anterior y superior a su oposición con el principio oscuro. Así, Schelling llama "amor" al principio que se identifica con la existencia de Dios, que "penetra todo" y "es todo en todo" 28. El principio oscuro o cólera fundamenta la existencia, y la luz o el amor realiza la existencia sometiendo al fundamento. Por debajo de ambos, el in-fundamento permanece como origen inmanente e inefable del proceso. Como vimos, la división del único y mismo ser en dos principios es para Deleuze testimonio del spinozismo schellingiano, que se traduce aquí en la vida de Dios (la unidad que enlazaba la potencia de existir con la potencia de pensar). La especificidad

\footnotetext{
${ }^{26}$ Puede verse, por ejemplo, en el Sistema del idealismo trascendental, donde Schelling sigue la armonía preestablecida de Leibniz antes que el paralelismo de Spinoza: "Cómo el mundo objetivo se acomoda a presentaciones en nosotros, y las presentaciones en nosotros al mundo objetivo, es ininteligible a menos que entre ambos mundos, el ideal y el real, exista una armonía preestablecida. Pero esta es impensable en sí misma a menos que la actividad por la cual el mundo objetivo es producido, es en el fondo idéntica con aquella que se expresa a sí misma en la volición, y viceversa" (SW II, 348; traducción nuestra). A partir de las Investigaciones, sería quizás más acertado hablar de una desarmonía en proceso de armonización progresiva, que manifiesta la identidad de un conflicto originario tanto del ámbito de la naturaleza como de las representaciones que tenemos de ella.

${ }^{27}$ Sobre esta noción en las Investigaciones, $c f$. SW I/7, 406 y ss. [279 y ss.]

${ }^{28}$ SW I/7, 408 [283]. Recordemos la centralidad del "amor y la cólera" como las dos potencias del Absoluto, mencionadas en el pasaje de Deleuze citado previamente.
} 
del desarrollo de la dinámica eterna de auto-génesis divina se da en todo su esplendor con la doctrina de las potencias, a la que pasamos a continuación.

\subsection{La Potenzenlehre}

En 1810, Schelling imparte sus Lecciones privadas de Stuttgart ${ }^{29}$, en cuyo texto se encuentra por primera vez su doctrina de las potencias como elemento estructurante del sistema. La Potenzenlehre schellingiana continúa la idea de las Investigaciones: la imposibilidad de la razón de constituir un sistema cerrado sobre sí a partir de un principio simple y la consecuente necesidad de un principio que implique heterogeneidad con respecto a sí mismo. Y esto sin renunciar a la idea de que el Absoluto es uno, y que todas las cosas emergen en y por él, siguiendo un despliegue gradual que no es ajeno al Absoluto mismo. La Potenzenlehre es la herramienta conceptual mediante la cual Schelling intenta dar cuenta de ese despliegue. Los protagonistas aquí son nuevamente esos principios en tensión que, en las Investigaciones, constituian las dos mitades de lo Absoluto, pero el objetivo no es ya explicar la esencia de la libertad humana, sino entrar de lleno en ese drama de la divinidad que en las Investigaciones solo se presentaba. El problema filosófico que subyace a ese drama sigue siendo el del cruce entre lo real y lo ideal: debe haber algo extraideal para que lo ideal se realice. La Idea, pensada como un mero universal abstracto, eterno e inmutable, o un reservorio de posibles, no puede generar por sí misma la particularidad de la existencia bruta, inmediata, mutable, contingente y corruptible. La existencia en ese estado "puro" es más bien "idea invertida" 30 , con lo cual remite a una dimensión más acá de la Idea que nos expulsa de ella.

La exposición de la doctrina de las potencias en sí misma es un tema poco frecuente en la bibliografia secundaria dedicada a Schelling, la cual tiende a privilegiar las caracterizaciones que de ella se encuentran en su filosofia de la mitología, o las comparaciones con el idealismo fichteano o hegeliano ${ }^{31}$. Con esto

\footnotetext{
29 De aquí en más, Lecciones.

30 Esta expresión, del propio Schelling, es retomada y revalorizada por Edward Allen Beach en un trabajo imprescindible para el estudio de las potencias schellingianas. Cf. Beach, E.A., The potencies of God(s). Schelling Philosophy of Mythology, Nueva York: State University of New York Press, 1993 , p. 96. Seguimos en varios puntos su riguroso análisis de la ontología de las potencias (que el autor desarrolla en ibid., p. 95ss.).

31 Siguiendo la presentación de Beach, las potencias de Schelling pueden verse desde una perspectiva puramente ideal - previa a su puesta en la existencia-como A, $\mathrm{A}^{2}, \mathrm{~A}^{3}$ : la primera potencia, A, como posibilidad ilimitada e indefinida, pura subjetividad; la segunda, como actividad limitante "pura" (sin nada que limitar), o pura objetividad; y la tercera potencia, $\mathrm{A}^{3}$, como actividad auto-limitante, que sintetiza las dos anteriores (cf. ibid., p. 116ss.). El análisis de Beach se mueve luego hacia la efectiva puesta en juego en la existencia de esas potencias ideales por medio de
} 
se arriesga a perder de vista la originalidad del planteo schellingiano: el principio es permanentemente heterogéneo con respecto a si mismo, y esa heterogeneidad implica que el sistema contiene un núcleo irracional irreductible. El indice de esta heterogeneidad necesaria debe residir ya al interior del primer principio, lo cual está claramente expresado por Schelling tanto en las Lecciones como en las Edades: el comienzo no es A, ni A=A, sino A=B. No se parte del absoluto ser, o de la absoluta auto-posición del ser por sí mismo, sino de una unidad de contrarios. Esto implica no una supresión (Aufheben) de la identidad, sino una duplicación (Doublirung) de la misma ${ }^{32}$, una identidad de la diferencia. Aquí A, principio ideal, y B, principio real, contienen en sí mismos la esencia original entera -Dios es en ambas-, pero su distinción formal en la identidad absoluta de esa esencia constituye, según Schelling, el único camino para llegar a la distinción real. Podemos encontrar en el inicio de la versión de 1815 de las Edades (la versión citada por Deleuze y que seguimos en este trabajo) una reflexión similar sobre la esencia divina: "Ser es peculiaridad, separación; mientras que el amor es la nada de la peculiaridad, no busca lo suyo, de ahí que por sí mismo no pueda ser ente. Del mismo modo, un ser de todos los seres carece por sí mismo de consistencia y no está portado por nada: es en sí mismo lo contrario de la personalidad, así que otra fuerza que tienda a la personalidad ha de hacerle de fundamento (Grund). Se requiere una fuerza de la mismidad, de la egoidad, igualmente eterna, para que el ser que es el amor exista como propio y para si”"33.

Vemos reaparecer entonces el esquema de las Investigaciones. En el contexto de las Edades, Schelling desarrolla desde una nueva perspectiva el drama de la revelación de Dios, con mayor detalle, dando nuevos nombres y figuras a sus momentos. A y B, respectivamente fuerza del amor y fuerza de

su “inversión”. De manera similar, para Odette Laffoucrière las potencias redefinen la estructura interna de la subjetivización del idealismo fichteano (si bien esto no implica una mera repetición de ese idealismo, sino una transformación del mismo motivado por una crisis de la razón): para ella, también, la primera potencia es sujeto, la segunda objeto, la tercera sujeto-objeto ( $C f$. Laffoucrière, O., "Schelling et les puissances", en: Les études philosophiques, 2 (abril-junio de 1974), pp. 183ss). Laffoucrière, sin embargo, no reduce a esto las potencias, y señala la complejidad metafísica de este esquema: la primera potencia corresponde a un ser más allá del ser, me on, ser de lo que puede ser, que no es mera negación del ser, ouk on (ibid., p. 184; como vimos en la cita de Diferencia y repetición, Deleuze retomaba este aspecto); la segunda es el ser que es, el ente; y la tercera, a la vez ser y poder ser, es decir, sintesis de las dos precedentes.

32 Cf. Schelling, F.W.J., Stuttgarter Privatenvorlesungen, SW I/7, 425.

33 Schelling F. W. J., Die Weltalter, SW I/8, 217 (seguimos la traducción de Jorge Navarro Pérez para la edición de Schelling, F.W.J., Las edades del mundo, Madrid: Akal, 2002, e indicamos entre corchetes al lado la paginación de la misma -en este caso, p. 177). 
la egoidad, o expansión y contracción, o afirmación y negación, constituyen el "ser primigenio" (Urwesen) ${ }^{34}$. Este envuelve simultáneamente ambos principios: es a la vez unidad y contraposición, su esencia es esa contradicción interna. "Sin contradicción", escribe Schelling, "no habría movimiento, no habría vida ni progreso, sino una detención eterna, un letargo de todas las fuerzas"35. La contradicción es el motor de la vida, e incluso Dios es una vida. El fundamento de la existencia divina (aquello únicamente sobre lo cual la existencia puede erigirse) es $\mathrm{A}=\mathrm{B}$, la naturaleza de Dios, que es el comienzo de su drama, la primera potencia ${ }^{36}$.

Esta potencia del fundamento se caracteriza por la preeminencia de la fuerza negadora, lo cual manifiesta una idea recurrente en Schelling desde las Investigaciones: si bien la libertad amorosa, luminosa, expansiva y afirmadora es la actividad que realiza la existencia, esta supone siempre ya ahí una necesidad egoísta, oscura, contractiva, negadora. En las Investigaciones, Schelling decía: "Todo nacimiento es un nacimiento desde la oscuridad a la luz; la semilla ha de ser hundida en la tierra y morir en las tinieblas a fin de que pueda alzarse una forma luminosa más hermosa y desarrollarse bajo los rayos del sol"37. La primera potencia es $\mathrm{A}=\mathrm{B}$, donde $\mathrm{B}$, fuerza contractiva, es la fuerza operante $\mathrm{o}$ dominante. La esencia divina, en este estadio, se cierra sobre sí misma. Ese estado de prevalencia de la negación, que precede -y posibilita- todo movimiento, es, en términos de la doctrina de las potencias, la Naturaleza. Y de la naturaleza es correcto decir que es necesidad ciega, pero no que es ausencia de espíritu. La naturaleza designa un predominio del cuerpo sobre el espíritu (más precisamente, del principio contractivo por sobre el expansivo) tal que el espíritu, bajo ese yugo, no se conoce a sí mismo. Esto no impide que, en cierto modo, pueda sentirse a sí mismo. Habría que decir entonces que la naturaleza es espiritu ciego, un estado en que el principio luminoso se encuentra como no-ente, pero tiende a la existencia (esta tendencia es precisamente su esencia). Encontrarse como no-ente es ya querer llegar al estado de ente, y este querer es para Schelling una pulsión inconsciente originaria de Dios. "Como un ser que no tiene nada fuera de sí no puede querer nada más que a sí mismo, el comienzo primero o incondicionado solo puede residir en el quererse a sí mismo.

\footnotetext{
34 SW I/8, 217 [181].

35 SW I/8, 219 [182]. La caracterización de la vida como suponiendo una necesaria contraposición figura también explícitamente en las Lecciones de Stuttgart (cf. SW, I/7, 432-35)

${ }^{36}$ Cf. SW I/8, 223 [185].

37 SW I/7, 360 [167].
} 
Pero quererse y negarse en tanto que ente son lo mismo"38. La primera potencia es, pues, un querer.

En esta voluntad asoma ya la segunda potencia. Si la negación en la primera es el principio de todo ente, el quererse a sí mismo es la fuerza del comienzo. Claro que esto no puede significar un comienzo en el tiempo: "[En Dios] el comienzo es un comienzo eterno, es decir, un comienzo que era comienzo desde toda la eternidad y que sigue siendo y que nunca deja de ser comienzo"39. Lo que surge de este comienzo eterno, a partir de la fuerza auto-negadora -y simultáneamente auto-generadora o auto-realizadora-, es la afirmación de eso que en la primera potencia aparecía negado, a saber, el principio afirmativo: lo ente se pone como ente ${ }^{40}$, en una afirmación de la afirmación que constituye la segunda potencia, $\mathrm{A}^{2}$. Ella es limitación del principio negador, y por lo tanto separación y posición efectiva de realidad como oposición. A=B y $\mathrm{A}^{2}$ forman asî una contraposición, exteriorizan el conflicto que la primera potencia contenía en sí, y se encuentran por tanto dispuestas a una unidad futura: $\mathrm{A}^{3}$, tercera potencia, y final eterno de ese movimiento puesto por el eterno comienzo de la primera potencia ${ }^{41}$. Si este estaba motivado por el querer afirmarse ante la negación de sí, aquel será la unidad a la cual tiende la contraposición entre la primera y la segunda potencia, el camino del amor hacia su hacerse uno en la auto-afirmación absoluta del todo.

Entre el comienzo y el final eternos de Dios se abre un conflicto eterno, un ciclo infinito de repetición de estas potencias en la naturaleza. De la primera potencia se asciende a la tercera, para volver a caer en la primera, y de ahí volver a elevarse. Esta parece ser la condición necesaria de la existencia eterna: si Dios, en su elevación potencial, anulara en el final la contradicción del comienzo, moriría, en tanto esa contradicción es lo que define la vida. En cambio, si tanto el comienzo como el final en Dios son eternos, también es eterno su ciclo. Dios es vida eterna, por ende, conflicto eterno, y este conflicto implica que la expansión o revelación va siempre acompañada de contracción u oscuridad. Si así no fuera, Dios perdería aquello que en sí mismo hace las veces de fundamento a su existencia. Con esto, Schelling pretende haber expresado el "concepto perfecto" de la naturaleza de Dios: "esa naturaleza es una vida que gira eternamente en torno a sí misma, una especie de círculo en que lo

${ }^{38} \mathrm{SW} \mathrm{I} / 8,224$ [185].

${ }^{39} \mathrm{SW} \mathrm{I} / 8,225[186]$.

${ }^{40} \mathrm{SW} I / 8,226[187]$.

${ }^{41}$ Cf. SW I/8, 227-8 [187-8]. 
más bajo va siempre a lo más alto, y lo más alto vuelve a lo más bajo"42. Si en las Investigaciones la necesaria contracción del comienzo estaba ilustrada en la imagen de la semilla, el ciclo entero (contracción-expansión-contracción...) encuentra aquí su imagen en la vida del árbol: "El árbol, por ejemplo, se impulsa continuamente de la raíz al fruto, y una vez que ha llegado a la copa lo vuelve a tirar todo, retorna al estado de esterilidad y vuelve a hacerse raíz, pero para volver a alzarse. Toda la actividad de la planta se dirige a la generación de la semilla, para volver a empezar en esta desde el principio y mediante un nuevo proceso progresante generar semillas y empezar de nuevo"43.

El ciclo que es la vida de Dios es así también el ciclo de toda vida, toda existencia finita replica la existencia divina. Esta última posee, sin embargo, la particularidad de contener de modo primigenio, y en estado de indistinción, todas las potencias (y todos sus resultados posibles): “Toda existencia viviente comienza por la inconsciencia, por un estado donde todo se encuentra indiviso, indiferenciado... caracterizado por la ausencia de una consciencia capaz de separar, distinguir, dividir. Es así como comienza la vida divina... Es un estado que hemos caracterizado como indiferencia de las potencias... [T]odo el proceso de la creación del mundo, que prosigue siempre bajo la forma del proceso vital en la naturaleza y en la historia, no es otra cosa que el proceso por el cual Dios toma más y más consciencia de sí mismo, el proceso de su personalización progresiva"44.

Del estado de indiferencia de las potencias al proceso de creación, algo debe acontecer para ordenar y guiar dicho proceso. La mera repetición del ciclo en el poner alternante de la naturaleza implica para Schelling una necesidad ciega que no puede generarse por sí misma. Como vimos, Schelling caracterizaba al "querer" en Dios como "comienzo incondicionado": en efecto, es la libertad en Dios aquello que se manifiesta en la ordenación de las potencias. Si de su indiferencia se pasa a un orden, esto ocurre en tanto ellas reconocen, en la libertad, un principio superior bajo el cual deben subordinarse. Ante lo ideal en Dios, las potencias manifiestan una diferencia de dignidad que las motiva a una "renuncia común y voluntaria" de cada una de ellas a ser la existencia completa, y tras la cual "se vuelve posible la posición separada, o que cada una pase a su potencia"45. Aquí se halla el fundamento de la repartición en lo

\footnotetext{
42 SW I/8, 229 [188].

43 SW I/8, 231 [190].

44 SW I/7, 432-3 [315]. El empleo de cursivas es nuestro.

45 SW I/8, 232-3 [190-1].
} 
existente de lo más alto y lo más bajo: la subordinación de lo real a lo ideal. La naturaleza reconoce su falta de dignidad respecto a la libertad ${ }^{46}$, y se rebaja para que el reino de los espíritus domine sobre ella.

Esto tiene por resultado que el ciclo eterno de las potencias se dé siempre como un paulatino ascenso hacia el principio de la luz. A=B se subordina a $\mathrm{A}^{3}$, pero este permanece todavía ligado a aquel siempre por mediación de $\mathrm{A}^{2}$, con lo que todos los momentos están en relaciones de copertenencia ${ }^{47}$; así, $A=B$ es el fundamento natural de la existencia en general (y de la naturaleza en particular), $\mathrm{A}^{2}$ el mundo de los espíritus que se erige sobre aquel, y $\mathrm{A}^{3}$ el alma del universo, vínculo de unificación entre las potencias anteriores ${ }^{48}$. Mientras que, como afirmaba Deleuze, podemos ver aquí representada la unidad de lo Absoluto análogamente a la unidad de la sustancia spinozista, es preciso notar que Schelling marca un punto de distanciamiento con Spinoza. En su intento por rechazar el carácter cosista de dicha sustancia, Schelling hace eco de Leibniz para afirmar una necesidad moral del universo. Dicha necesidad justificaría el dominio de una potencia por sobre otra (el espíritu sobre la naturaleza): "Uno de los aspectos más satisfactorios de la filosofia de Leibniz..., es el reconocimiento de leyes de la naturaleza necesarias moral y no geométricamente, pero por lo mismo, tampoco arbitrarias..., estas leyes son la prueba de la existencia de un ser supremo, inteligente y libre, en contra del sistema de la necesidad absoluta"49.

Además de estos órdenes ontológico y moral, el sistema de las potencias implica también un orden temporal. Así como toda cosa tiene su comienzo en la negación o contracción, y su vida es una expansión a partir de ella y un retorno a ella, las potencias representan las dimensiones de la temporalidad, periodos de la revelación de Dios que se manifiesta en las cosas. Tanto Dios como las criaturas tienen un pasado en aquello que es puesto como negado y superado $(A=B)$. El presente es expansión $\left(A^{2}\right)$ sobre ese pasado contraído, y hacia un futuro que los unifique $\left(\mathrm{A}^{3}\right)$. Así como Dios tiene un pasado eterno en su principio negativo y un futuro eterno en su unificación absoluta, cada cosa, como el árbol, tiene su tiempo finito particular, que replica esta estructura eterna de la temporalidad ${ }^{50}$. Y si bien el ciclo se repite indefinidamente, sus repeticiones

\footnotetext{
46 "Ningún ser inferior, pero receptivo a lo supremo, puede participar del mismo sin una división en sí mismo, sin una simultanea humillación de la parte más baja” (SW I/8, 240 [195]).

47 Cf. SW I/8, 240 [195]

48 Cf. SW I/8, 252 [203].

49 SW I/7, 396 [253].

${ }^{50} C f$. SW I/8, 259ss. [207ss.].
} 
no son mecánicas o idénticas, sino que implican variaciones y expresan cada una un ascenso. El desarrollo de cada cosa finita expresa un grado del propio desarrollo progresivo de Dios. De este modo -y esto es minuciosamente desarrollado en las Lecciones- las potencias de Dios se reencuentran al interior de cada estadio de su desarrollo, desde la naturaleza (cuya progresión va de las fuerzas dinámicas básicas: magnetismo, electricidad, quimismo; a la generación de la materia, y en ella, a su división en inorgánica y orgánica) ${ }^{51}$, pasando por el espiritu, cuya realización en la existencia está en el hombre (el cual posee en sí las potencias de la afectividad, la espiritualidad y el alma, y cada una de ellas a su vez contienen, respectivamente, tres potencias: tristeza, deseo y sentimiento; egoísmo, entendimiento y voluntad; locura, filosofia y virtud) ${ }^{52}$, hasta la suprema identidad de ambos en el amor divino.

Toda esta graduación jerárquica y teleológica de la historia y los productos de Dios, teñida de aspectos morales, parece alejarnos del spinozismo. ¿Es, pues, Schelling "spinozista, cuando designa a Dios como A"? El problema de Spinoza, según Schelling, es desconocer el conflicto implicado en Dios, y, por consiguiente, -como vimos- concebirlo como esencia muerta, como cosa. Su mérito, en cambio, es haber planteado como nadie el equilibrio de las fuerzas primigenias, por lo cual Spinoza es "el único sostén de la verdadera ciencia a través de todos los tiempos recientes" ${ }^{53}$. El principio básico de Spinoza, la diversificación de una y la misma sustancia en una diversidad de atributos y modos, se desarrolla en la filosofia de Schelling como una serie de potencias, a partir de una fuerza de contracción hacia lo uno y una fuerza de expansión hacia el todo. "Lo atraído es la naturaleza eterna, el todo; lo atrayente es uno; el conjunto, que podemos designar como, es el uno y todo (غ่v kai пáv), en conexión estrecha" ${ }^{4}$. En esta fórmula general, donde se aprecia la identidad de los opuestos A y $\mathrm{B}$, de ellos con $\mathrm{A}^{2}$, y la sumisión del conjunto a $\mathrm{A}^{3}$, la $\mathrm{B}$ que queda por fuera del paréntesis es el índice de una nueva contracción y un nuevo comienzo, con la doble cualidad de B de ser fuerza negadora y el fundamento del despliegue. El ciclo implica entonces una "caída", un pasaje de lo alto a lo bajo, lo cual parecería indicar una contradicción con el progreso de la vida divina. Lejos de ello, la caída es condición misma de un nuevo ascenso,

\footnotetext{
51 Temas que Schelling había trabajado previamente ya en sus trabajos sobre filosofia de la naturaleza.

${ }^{52}$ Cf. SW I/7, 465ss.

53 SW I/ 8, 340 [256]. La cita continúa: "De ahí que no fuera un milagro que cada nueva agitación poderosa haya tenido que partir de él y volver a él”.

54 SW I/8, 312 [239].
} 
diferente -superador- del anterior: "Cuando la vida pasa a una nueva época, es necesario que vuelva a hacer un comienzo, y es inevitable que este comienzo o este primer nivel de la nueva época parezca un retroceso frente al supremo de la época precedente: comparadas potencia con potencia, la siguiente se encuentra más abajo que la precedente, ya que esta es en su tiempo necesariamente una potencia superior que aquella en el suyo; pero comparados tiempo con tiempo, época con época, aquella se encuentra claramente más alto. Tales retrocesos aparentes son, pues, necesarios en la historia de la vida"55.

En términos deleuzianos -como sugería el pasaje citado en I.2, y como veremos a continuación-, este aparente retroceso puede traducirse en la despotenciación necesaria para la génesis de una nueva potencia, el contacto entre la individuación y la Idea. Este proceso que en Schelling se da como un progresivo avance teleológico en la auto-constitución de la identidad divina -y que parece en más de una oportunidad alejar a Schelling de Spinoza-no puede ser transpolado sin más a la filosofia deleuziana, pero nos permitirá establecer algunas hipótesis sobre ciertos puntos problemáticos de ella. A continuación, retomamos el problema de las potencias deleuzianas, para ponerlo en relación con lo hasta aquí desarrollado sobre las schellingianas.

\section{Potencia e inmanencia, de Schelling a Deleuze}

\subsection{La determinación como auto-génesis inmanente: Idea e intensidad}

Nuestro problema de partida refería a los dos usos de "potencia" en la filosofia deleuziana -esto es, la enésima potencia de una singularidad ideal o pre-individual, y potencia de un individuo de ir hasta el final de su capacidadbajo la hipótesis de que en esa noción Deleuze sugiere un vínculo entre lo virtual y lo actual. Profundizar en esta hipótesis nos obliga a internarnos en la escabrosa ontología que Deleuze desarrolla en los capítulos IV y V de Diferencia y repetición. Argumentaremos aquí que el mencionado doble uso del concepto de potencia remite a una duplicidad de perspectivas interdependientes: la de la Idea, donde la noción de potencia se define como "pura potencialidad" en un

138 campo trascendental de singularidades pre-individuales, y la de la intensidad, en la que la potencia se define como una profundidad sin fondo que surge de una comunicación entre series heterogéneas cuyos términos remiten a su vez a otras series heterogéneas, de manera tal que se constituye un campo de indivi-

55 Ibid.

ARETÉ Revista de Filosofía, v. XXXIII, 1, 2021 / e-ISSN 2223-3741 
duación. Mediante esta duplicidad de procesos ontológicos inter-relacionados, Deleuze intenta dar cuenta del desarrollo de una individuación que efectúa en la existencia actual las determinaciones pre-individuales de la Idea, o singularidades. El esquema schellingiano converge con la formulación de esa doble perspectiva en la noción de potencia ${ }^{56}$. En efecto, la Idea deleuziana no se basta a sí misma para ponerse en el ser sensible actual. La última sección del capítulo IV de Diferencia y repetición se refiere a la puesta en la existencia de la Idea como un proceso de dramatización ${ }^{57}$. Esta dramatización está asociada a la efectuación de la "pura potencialidad" propia de la determinación virtual de la Idea ${ }^{58}$. La pregunta que el análisis de la Idea deja planteada es, entonces, qué es aquello que efectúa la puesta en acto, o bien, quién dramatiza la Idea, quién efectúa sus determinaciones.

De este modo, y al igual que en el caso de Schelling, una instancia "extraideal" es necesaria para dar cuenta de la existencia concreta. Algo en la Idea nos remite a algo que no es la Idea misma. Según lo desarrollado en el capítulo V de Diferencia y repetición, la intensidad será el agente de ese movimiento de dramatización. Hemos visto cómo, según Schelling, las potencias implicaban un orden de desarrollo del Absoluto a partir de dos fuerzas contrapuestas, orden que se repetía a su vez en cada una de sus manifestaciones finitas de manera análoga, de manera tal que se configuraba una totalidad orgánica orientada teológica y teleológicamente, que suponía la profundidad sin fondo de un in-fundamento donde toda orientación y distinción (u oposición) se hundian en indiferencia ${ }^{59}$.

\footnotetext{
56 Si bien Schelling no es una de las fuentes canónicas del pensamiento deleuziano, varios autores han recorrido distintos aspectos de su relación. Entre ellos, sin embargo, no hemos encontrado desarrollos específicos sobre el tema de la potencia, a excepción de algunas menciones más bien superficiales en los trabajos de Jason Wirth ( $c f$. Wirth, J., The Conspiracy of Life, Nueva York: State University of New York Press, 2003, p. 185; y Wirth, J., Schelling's Practice of the Wild. Time, Art, Imagination, Nueva York: State University of New York Press, 2015, en particular pp. 61ss.).

57 Sobre el concepto de dramatización como dinamización espacio-temporal, cf. Deleuze, G., Différence et répétition, pp. $276 \mathrm{ss}$.

58 “¿Qué es lo que efectúa... el elemento de potencialidad de la Idea?”, pregunta Deleuze en las últimas líneas de ese capítulo, y se responde: "Sin duda la dramatización, pre-cuantitativa y pre-cualitativa” (ibid., p. 285). A vuelta de página, entramos en la descripción del agente de esa dramatización, la intensidad.

59 Es seguramente este carácter teo-teleológico y moralizante de Schelling lo que lleva a Deleuze a declarar sobre Schelling que "su sin-fondo no soporta la diferencia" (ibid., 354); y años más tarde, que su planteo "es arborescente", y que es "justamente por eso que no me siento boehmeano ni schellingiano" (Deleuze, G., Cine II. Los signos del movimiento y el tiempo, Ires, P. y S. Puente (trads.), Buenos Aires: Cactus, 2011, p. 504). Usando el lenguaje de Mil mesetas, lo arborescente se distingue de lo rizomático, como un sistema cerrado y organizado de manera fija se distingue del movimiento de un sistema abierto, múltiple y pasible de diferentes órdenes no predeterminados. Esta calificación de "arborescencia" por parte de Deleuze es retomada en otros términos por Alberto Toscano, quien encuentra en la filosofia de Schelling una "imagen orgánica
} 
En el caso de Deleuze, si cabe hablar de un Absoluto, ese lugar está reservado a la absoluta diferencia como principio genético de la experiencia. Así, el Absoluto nunca se manifiesta, como en Schelling, bajo la forma de un Individuo eterno o una totalidad orgánica en proceso de personalización -que produce y acoge en sí partes análogas a sí misma-, sino como una actividad de diferenciación radicalmente des-centrada -o mejor: des-centrante- que recorre y vivifica toda diferencia individual. En la medida en que la naturaleza de la Idea es la pura diferencia, no es una mera contracara irracional o material lo que su puesta en la existencia demanda. Sin embargo, de acuerdo a lo dicho, ese absoluto también puede considerarse como estructurado en dos "mitades": la Idea y la intensidad. Veamos cómo ambas poseen una vinculación estrecha con la noción de potencia, la cual las articula en la génesis y devenir de un individuo.

La Idea deleuziana es caracterizada según el modelo del cálculo diferencial, como un complejo de coexistencia de elementos diferenciales pre- o subrepresentativos (así como las magnitudes diferenciales son "evanescentes", o "ceros"), carentes de forma sensible y de significación conceptual, pero provistos de un principio de determinabilidad que los vuelve capaces de engendrar determinaciones a partir de sus relaciones en una sintesis recíproca. Estas determinaciones son singularidades, y-siempre en el marco de la modulación matemática del concepto de Idea- se caracterizan por ser un punto límite para una serie de potencias ${ }^{60}$. Esto es, una sumatoria de la forma $a x+b x^{2}+c x^{3}+d x^{4} \ldots$, etcétera, donde $a, b, c, d \ldots$, son coeficientes calculados mediante relaciones diferenciales, y la variable $x$ se repite elevada a una potencia superior en cada término. Las singularidades son valores específicos que, asignados a la variable, vuelven irresoluble a la serie y exigen la generación de una nueva serie. Para una función matemática, las singularidades son puntos de inflexión, máximos o mínimos, asíntotas, polos, etcétera. Es decir, son límites o puntos críticos en torno a los cuales se define el comportamiento global de los segmentos de puntos regulares de la curva descripta por la función. Al llegar a una singularidad, la

del pensamiento", en la medida en que ella presenta una visión teleológica del Absoluto, donde "la convergencia o indiferencia entre pensar y ser no es, en última instancia, algo a ser construido o experimentado en los movimientos del plano de inmanencia, es algo puesto incondicionalmente" (Toscano, A., "Philosophy and the Experience of Construction", en: Welchman, A. y J. Norman, J., The New Schelling, Londres: Continuum, 2004, p. 124; traducción nuestra).

${ }^{60}$ Cf. Deleuze, G., Différence et répétition, pp. 226-228. A propósito del concepto de serie de potencias en Deleuze, remitimos a Santaya, G., "Serie, singularidad, diferencial. La matemática como fuente del empirismo trascendental", en: Ferreyra, J. (ed.), Intensidades deleuzianas. Deleuze y las fuentes de su filosofía III, Adrogué: La cebra, 2016, pp. 85-103. 
serie de potencias que define la función hasta ese punto se transforma, dando lugar a una nueva serie.

Una serie de potencias se prolonga entonces entre dos singularidades: por un lado, las singularidades son puntos de articulación para distintas series, configurando una estructura que relaciona los intervalos regulares de una curva; por otro lado, la serialidad es el modo por el cual las singularidades se prolongan y comunican entre sí. Singularidades y series se enlazan y presuponen mutuamente, relacionadas a través de la "pura potencialidad" de la Idea61. Esta se vincula con la propiedad de una relación diferencial de "despotenciar" una función para obtener una nueva función (es decir, una función derivada, que será de un grado inferior a la primitiva), permitiendo calcular los sucesivos coeficientes de una serie de potencias. La despotenciación en la Idea implicaría, entonces, la capacidad de generar series ordenadas de términos (individuos) heterogéneos que prolongan una cierta variación regular entre límites o singularidades, y que, llegados a estos límites, suponen la producción de una nueva serie, un nuevo tipo de variación, prolongable a su vez hasta un nuevo límite. La determinación, definida asi como co-dependencia de lo singular y lo regular (o serial), reemplaza entonces la caracterización como subordinación de lo particular bajo lo general, propia de la representación. Al mismo tiempo, ella hace de la pluralidad o multiplicidad la norma (reemplazando la unidad abstracta del género por el universal concreto de la diferencia): una singularidad supone siempre una multiplicidad de puntos regulares en los que se extiende, y estos, a su vez, se proyectan necesariamente hacia otra (o, mejor, otras) singularidad(es).

Las singularidades se caracterizan como puntos inextensos o acontecimientos intempestivos que permiten configurar un cierto régimen de espacios y duraciones (por ejemplo, el espacio de una curva matemática). El complejo de relaciones diferenciales y singularidades conforma la estructura virtual o ideal que entra en un proceso de dramatización espacio-temporal, protagonizado por la intensidad. Esta se define como una puesta en comunicación de series heterogéneas (compuestas a su vez de términos heterogéneos) ${ }^{62}$, y describe la dinámica de la individuación. Todo individuo (un sujeto humano, pero también un animal, una célula, un planeta, una piedra, una curva matemática, una nación o un Estado...) supone la estructura diferencial de la Idea como fuente de sus determinaciones, singularidades pre-individuales que marcan puntos de ruptura y apertura al curso de series regulares que definen su campo de

${ }^{61}$ Cf. Deleuze, G., Différence et répétition, p. 226.

62 Cf. ibid., p. 286ss. 
individuación, sus configuraciones espacio-temporales, sus posibles cursos de acción. La Idea, entonces, no es ya (como lo era A en la primera potencia schellingiana) un principio luminoso que opera una reconducción a una cierta unidad $\left(\mathrm{A}^{3}\right)$ ya presupuesta en un principio (la $A$ en $A=B$ ), sino una fisura que corroe la fijeza o la auto-clausura de una identidad individual, abriéndola permanentemente a un plano virtual de singularidades que la fuerzan a nuevos cursos posibles de individuación, a veces compatibles, a veces incompatibles con la individualidad de base. De este modo, no es la Idea que debe suponer tras de sí un in-fundamento, sino el individuo quien debe suponer ante sí la Idea, como "des-fondamiento universal" 63 , quiebre de su identidad y apertura al campo problemático virtual, fuente del devenir que lo hace ser (es decir, poder).

La intensidad, por su parte, no se reduce (como el principio B schellingiano) a una negación de la Idea. Ella remite a una actividad comunicante de series heterogéneas, subyacente a las cualidades y extensiones perceptibles y representables. Bajo la supuesta simplicidad y homogeneidad de estas, la intensidad permanece como una profundidad inagotable de diferencias en tensión. En la caracterización deleuziana de esta profundidad intensiva, Schelling reaparece en una vaga referencia, en relación al problema de la génesis de las dimensiones espaciales ${ }^{64}$. Deleuze recurre a la noción de in-fundamento para caracterizar esta profundidad original intensiva, de la cual deriva la extensión y la duración empíricas. La profundidad no tiene fondo, es una fuente inagotable de distancias que dotan al clásico esquema perceptivo "forma-fondo" de un espesor indefinido, que se determina como ordenación de diferencias mediante series (articuladas, como vimos, por singularidades): "la diferencia

\footnotetext{
63 Esta noción aparece en Diferencia y repetición vinculada al quiebre radical del orden representativo y la emergencia de la pura diferencia expresada como Eterno Retorno; $c f$., por ejemplo, ibid., p. 261. En este sentido, Amanda Núñez Cortés señala la necesidad de traer a Hölderlin como fuente privilegiada del poskantismo deleuziano, siendo solo el poeta quien señala la necesidad de esta ruptura radical hacia el afuera en todo sistema: "Hölderlin busca una grieta sistémica no viciada de 'Uno' ni de tiempo-interioridad. Busca un afuera que libere al sistema y a la vida misma de su encerramiento, encontrado salidas hacia el porvenir y la politica. Por ello debe salir de la lógica de los fines dados de antemano, así como de la estricta necesidad fáctica del pasado que se narra y de la organicidad de este absoluto cerrado en sus abismos y sin posibilidad de alteración donde terminaba Schelling" (Núñez Cortés, A., "La grieta del sistema: Hölderlin entre Schelling y Deleuze", en: Logos: Anales del seminario de metafisica, v. XLV, 2012, p. 156.). Sobre la influencia shellingiana en el concepto deleuziano de "sin-fondo", puede verse Rodríguez, L., "Gilles Deleuze: el Ungrund en lengua francesa", en Ideas. Revista de filosofia moderna y contemporánea, 8 (abril de 2019), pp. 186-211.

64 "Schelling sabía decirlo: la profundidad no se agrega desde afuera a la altura y al ancho, sino que permanece enterrada como el sublime principio del diferendo que las creó" (Deleuze, G., Différence et répétition, p. 296).
} 
en profundidad se compone de distancias, pero la "distancia" no es meramente una cantidad extensiva, sino una relación asimétrica indivisible, de carácter ordinal e intensivo, que se establece entre series de términos heterogéneos" ${ }^{65}$. Y, si bien la intensidad no remite a la negación, podemos encontrar una afinidad entre ella y el principio B schellingiano, en tanto este es contracción, abismo y fundamento del pasado en la estructura de los tiempos. También la profundidad envuelta en toda extensión es, según Deleuze, correlativa de la síntesis temporal del pasado ${ }^{66}$, y guarda con la pura potencialidad ideal una relación de fundamento: "la potencia de la intensidad (profundidad) está fundada en la potencialidad de la Idea" ${ }^{67}$. Es por esto que podemos concluir que la pura potencialidad de la Idea, que generaba singularidades comunicables por series regulares, funda la profundidad o potencia intensiva, como comunicación efectiva entre series que determinan la multiplicidad de devenires potenciales asociados a un proceso individuación, abriéndolo al porvenir.

\section{Conclusión: individuación, potencia e inmanencia más allá de Schelling}

Ambos usos de la potencia en Deleuze confluyen entonces en la trama de la individuación, mediante la pura potencialidad ideal y la potencia de la intensidad. La potencia de una singularidad como capacidad de ponerse de una vez como multiplicidad (" $n$ veces") funda los límites dentro de los cuales se desarrollan las series comunicantes propias de un proceso de individuación. La multiplicidad solo es un tumulto informe y estéril desde el punto de vista de la identidad conceptual (que se queda detenida en el producto, sin acompañar el proceso de producción), pero es una pluralidad inagotable de diferencias ordenables desde que se la capta como indisociable de una singularidad que se pone como potencia de producción de repetición. La multiplicidad se determina así como un complejo de auto-determinación inmanente, que modula desde adentro un proceso de individuación y lo impulsa más allá de sí mismo, hacia nuevos regímenes de determinación e individuación. El individuo que actúa según el máximo de su capacidad recorre las series fundadas en sus singularidades constitutivas, repite estas singularidades en los términos heterogéneos de las series que lo prolongan y lo desarrollan, conduciéndolo a sus límites ("hasta el final de lo que puede"), y "saltando", o constituyendo nuevos limites, en la

\footnotetext{
${ }^{65}$ Ibid., p. 306.

66 Ibid.

${ }^{67}$ Ibid., p. 315. Las cursivas son nuestras.
} 
medida en que una nueva serie subtiende su devenir. El salto como superación de límites se da entonces en un devenir entre series, y cuanto mayor capacidad de "saltos", mayor apertura a devenires y conexiones, mayor efectuación de potencia, más individuaciones compondrán con ese proceso.

Nada en esto implica un orden teleológico preestablecido, ni una necesidad moral, pero sí una necesidad ontológica y una apuesta ético-política. Necesidad ontológica, dado que lo pre-individual rodea incesantemente al individuo como los infinitos senderos que bifurcan sus devenires posibles, comprometiéndolo en metamorfosis diversas. Apuesta ética, pues si ser es devenir, solo el individuo capaz de efectuar su potencia pre-individual sobrepasará sus límites, abriéndose a nuevos regímenes de individuación; en cambio, aquellos que solo dirigen sus impulsos a la conservación de lo dado fijan el devenir, llevándose a su mínima potencia. $\mathrm{El}$ arte de la existencia reside en la selección y el cuidado de las potencias: qué efectuar, qué serie prolongar, en qué dirección, qué conservar, qué comunicar, dónde disolverse, dónde fijarse. Todo el proyecto ético que Deleuze y Guattari emprenderán en Mil mesetas estará inspirado en este arte, en el cual una redefinición del concepto de prudencia ocupa un lugar fundamental. La inmanencia, en tanto campo trascendental, es el plano donde coexisten todos estos movimientos posibles: no es la intensidad como potencia de sentir la que es inmanente a la Idea, ni esta, como potencia de pensar, la que es inmanente a la intensidad. Idea e intensidad son el plano de inmanencia, operando por debajo del plano extensivo o empírico; y la inmanencia no es inmanente sino a sí misma (en cuanto se busca un concepto al cual las cosas serian inmanentes, se traiciona, se cosifica la inmanencia) ${ }^{68}$. Y la inmanencia es, ante todo, potencia, capacidad de pasaje o de pliegue entre ser y pensar, ${ }^{69}$ entre intensidad e Idea.

También en Schelling la inmanencia es el motivo por el cual el individuo se descubre en comunión con un orden supra-individual que lo rebasa y lo fundamenta, y en virtud del cual es capaz de constituir conexiones nuevas, desarrollarse junto a otros individuos conformando procesos de individuación superadores de la individualidad de base. ¿Qué decir entonces de la objeción a la inmanencia que señalamos al comienzo de este artículo? Desde una

\footnotetext{
${ }^{68}$ Sobre el plano de inmanencia como condición de todo pensamiento y la traición de la filosofia al plano, cf. Deleuze, G. y F. Guattari, Qu'est-ce que la philosophie?, pp. 48ss.

${ }^{69}$ Pierre Montebello ha escrito páginas interesantes sobre el concepto de plano de inmanencia como pliegue entre ser y pensar, caracterizándolo como el "absoluto" deleuziano: $c f$. Montebello, P., Deleuze. La passion de la pensée, París: Vrin, 2008, pp. 40ss.
} 
perspectiva deleuziana, lo característico del concepto de inmanencia es que ella consiste en algo "a construir" y "a experimentar", siempre una tarea o una actividad situada en ciertas condiciones empíricas ya individuadas, que guardan una pluralidad de potencialidades a explorar. La actividad de cada ente efectivamente existente se funda en el campo genético pre-individual, y en el desafio de componerse con otros procesos de individuación a partir de nuevas singularidades, conformando un devenir. La pura inmanencia es causa de la disgregación de todo orden individual o finito, pero también de la génesis de nuevos órdenes, y en esa disgregación y génesis no queda lugar para la indiferencia ontológica, epistémica, ética o política. Al contrario, solo hay lugar para los individuos que seleccionan sus movimientos y desarrollan su potencia hasta el final, que no se aferran a los límites sino para afirmarse en un régimen de individuación que favorezca la multiplicidad de conexiones, la mutua apertura entre sus elementos constitutivos, la destrucción de las fuerzas que traban su capacidad de actuar y la auto-organización de sus partes.

Así, la aceptación de la opresión del capitalismo global o el quietismo o fatalismo moral se ven puestos en entredicho; al mismo tiempo, el propio capitalismo se erige como un campo de inmanencia que impone modos de individuación y subjetivación tales que unos aumentan su potencia a costa de la disminución de la de los otros (respectivamente, los flujos de capital y los flujos de trabajo, como Deleuze y Guattari analizan en El Anti-Edipo). Todo proceso de individuación guarda por definición un campo de potenciales que lo comunican con la producción de nuevos individuos en potenciación recíproca. La lucha política debe estar orientada a la construcción de un cuerpo social consistente en una re-selección de las partes constitutivas a ser cuidadas y potenciadas. Este es, en efecto, el horizonte de la lucha práctica, la lucha por la existencia para las individuaciones sometidas, cuya potencia de actuar es oprimida por el régimen socio-histórico imperante. Creemos que la ontología deleuziana de la potencia, en este sentido, brinda herramientas teóricas insoslayables para pensar ese horizonte pragmático. En definitiva, es nuestra tarea abierta, en cada caso necesaria y permanentemente retomada, el trazar un plano donde las fluctuaciones de nuestros afectos y los devenires de nuestras individuaciones redunden en una sostenida efectuación de nuestra potencia.

Recibido: 28/07/2020

Aceptado: 24/12/2020 


\section{Bibliografia}

Beach, E. A., The potencies of God(s). Schelling Philosophy of Mythology, Nueva York: State University of New York Press, 1993.

Clisby, D., “¿El dualismo secreto de Deleuze?”, en: Ideas, Revista de filosofía moderna y contemporánea, 4 (2016), pp. 120-148.

Deleuze, G., Spinoza et le problème de l'expression, París: Les éditions de minuit, 1968.

Deleuze, G., Différence et répétition, París: PUF, 1968.

Deleuze, G. y F. Guattari, Qu'est-ce que la philosophie?, París: Les éditions de minuit, 1991.

Deleuze, G., Cine II. Los signos del movimiento y el tiempo, Ires P. y S. Puente (trads.), Buenos Aires: Cactus, 2011.

Hegel, G.W.F., Fenomenología del Espíritu, Buenos Aires: Fondo de Cultura Económica, 2009.

Jacobi, F.H., "Cartas sobre la doctrina de Spinoza al señor Moses Mendelssohn”, en: El ocaso de la ilustración. La polémica del spinozismo, Solé, M. J. (trad.), Bernal: Universidad Nacional de Quilmes 2013.

Laffoucrière, O., "Schelling et les puissances", en: Les études philosophiques, 2 (abriljunio de 1974), pp. 171-186.

Leyte, A., Las épocas de Schelling, Madrid: Akal, 1998.

Montebello, P., Deleuze. La passion de la pensée, París: Vrin, 2008.

Núñez Cortés, A., "La grieta del sistema: Hölderlin entre Schelling y Deleuze", en: Logos: Anales del seminario de metafisica, v. XLV (2012), pp. 145-161.

Rodríguez, L., "Gilles Deleuze: el Ungrund en lengua francesa", en Ideas. Revista de filosofia moderna y contemporánea, 8 (abril de 2019), pp. 186-211.

Santaya, G., "Serie, singularidad, diferencial. La matemática como fuente del empirismo trascendental", en: Ferreyra, J. (ed.), Intensidades deleuzianas. Deleuze y las fuentes de su filosofia III, Adrogué: La cebra, 2016, pp. 85-103.

Schelling, F.W.J., Sämmlitche Werke, Schelling, K.F.A. (ed.), Stuttgart y Augsburgo: Cotta, 1856-1861.

Schelling, F.W.J., Investigaciones filosóficas sobre la esencia de la libertad humana y los objetos con ella relacionados, Barcelona: Anthropos, 1989.

Schelling, F.W.J., Las edades del mundo, Madrid: Akal, 2002.

Spinoza, B., Ética demostrada según el orden geométrico, Ciudad de México: Porrúa, 1997.

Toscano, A., "Philosophy and the Experience of Construction", en: Welchman, A. y J. Norman (eds.), The New Schelling, Londres: Continuum, 2004, pp. 106-127.

146 Wirth, J., The Conspiracy of Life, Nueva York: State University of New York Press, 2003.

Wirth, J., Schelling's Practice of the Wild. Time, Art, Imagination, Nueva York: State University of New York Press, 2015.

Zizek, S., Órganos sin cuerpo. Sobre Deleuze y sus consecuencias, Valencia: Pre-textos, 2015. 